\title{
A review of applications of satellite SAR, optical, altimetry and DEM data for surface water modelling, mapping and parameter estimation
}

\author{
Z. N. Musa ${ }^{1}$, I. Popescu ${ }^{1}$, and A. Mynett ${ }^{1,2}$ \\ ${ }^{1}$ UNESCO-IHE Institute for Water Education, Delft, the Netherlands \\ ${ }^{2}$ Department of Civil Engineering, Technical University Delft, Delft, the Netherlands
}

Correspondence to: Z. N. Musa (z.musa@unesco-ihe.org)

Received: 22 April 2015 - Published in Hydrol. Earth Syst. Sci. Discuss.: 8 May 2015

Revised: 24 July 2015 - Accepted: 21 August 2015 - Published: 1 September 2015

\begin{abstract}
Hydrological data collection requires deployment of physical infrastructure like rain gauges, water level gauges, as well as use of expensive equipment like echo sounders. Many countries around the world have recorded a decrease in deployment of physical infrastructure for hydrological measurements; developing countries especially have less of this infrastructure and, where it exists, it is poorly maintained. Satellite remote sensing can bridge this gap, and has been applied by hydrologists over the years, with the earliest applications in water body and flood mapping. With the availability of more optical satellites with relatively low temporal resolutions globally, satellite data are commonly used for mapping of water bodies, testing of inundation models, precipitation monitoring, and mapping of flood extent. Use of satellite data to estimate hydrological parameters continues to increase due to use of better sensors, improvement in knowledge of and utilization of satellite data, and expansion of research topics. A review of applications of satellite remote sensing in surface water modelling, mapping and parameter estimation is presented, and its limitations for surface water applications are also discussed.
\end{abstract}

\section{Introduction}

Hydrological data collection still remains a difficult task nowadays due to non-availability of measurement devices, inaccessibility of the terrain and limitations of space/time (Quin et al., 2010; Pereira-Cardenal et al., 2011). A good alternative to overcome these difficulties is use of satel- lite remote sensing, which can give a synoptic view of target areas (Fig. 1) and measure target surface changes and therefore provide information needed for hydrological studies, river basin management, water hazard/disaster monitoring/prevention and water management, etc. Through the science of remote sensing, information about an object can be obtained without coming into direct contact with it (Lillesand et al., 2004). This capability works by measuring electromagnetic energy reflected by or radiated from objects on the Earth's surface (Fig. 1), in such a way that the difference in reflectivity of objects enables recognition/detection and isolation of each type/class (Fig. 2).

Remotely sensed data are of two types, depending on the main source of energy. Passive remote sensing depends on natural energy from the Sun. Active remote sensing uses controlled energy sources from instruments beaming sections of the electromagnetic spectrum. Imagery obtained via instruments that measure reflectance from the Sun is known as optical imagery. Optical imagery from satellites is therefore acquired during the day since it depends on the reflections of sunlight from objects on the Earth's surface in the absence of cloud cover. Depending on the mission specifications, satellites are placed on different kinds of orbits around the Earth. The orbits include low Earth orbit (LEO), medium Earth orbit (MEO), and geo-synchronous orbits (GSO); variations of these classes of orbits are the polar orbit, the geostationary orbits, the Molniya orbit and the Sun-synchronous orbit. Most optical satellites used for hydrological applications are in near-Earth orbits and are therefore able to provide detailed data at high ground (e.g. Fig. 1), although the best-resolution 


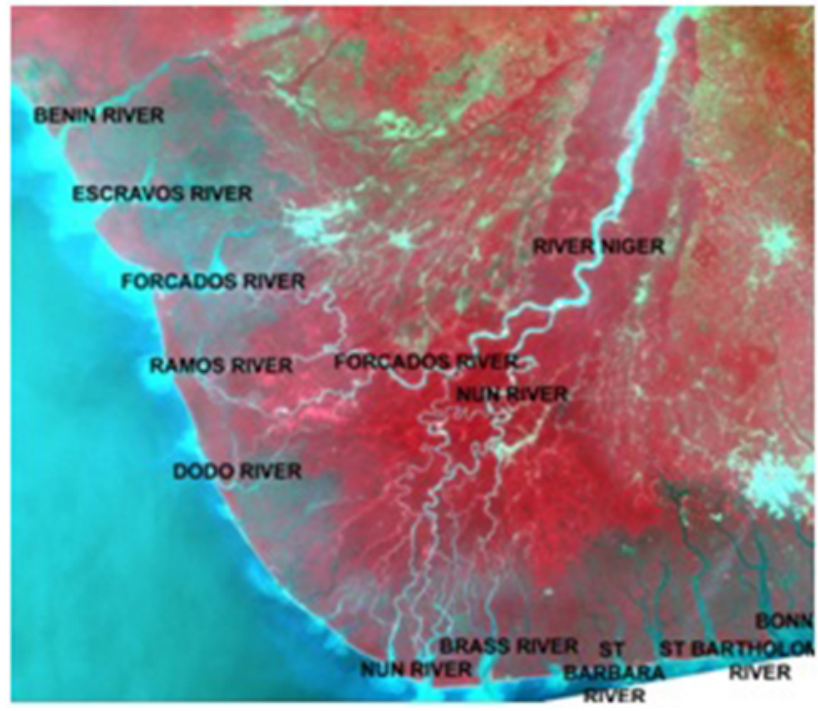

Figure 1. NigeriaSatX satellite image showing rivers in the Niger delta.

data are usually not freely available and are expensive to obtain. Due to this detailed resolution, optical satellite imagery is used for inundation mapping, drainage mapping, disaster monitoring, land-use/land-cover change analysis, etc. (Owe et al., 2001).

Active remote sensing can provide data as imagery (e.g. radar), and in the form of pulse measurements (e.g. altimeters and scatterometers). Radar is an active source of remote sensing data which acquires data via instruments that emit radar signal towards the object of interest and measure the reflected energy from the object. Radar can penetrate cloud cover and can be acquired at any time, independent of availability of sunlight. The penetration characteristic of the SAR satellites enables measurement of soil moisture in bare areas, making it useful for land-use and land-cover studies as well as Earth observation and monitoring (Owe et al., 2001). SAR is a side-looking instrument that sends out signals inclined at an angle. For water bodies, the reflectivity of SAR waves is spectacular, giving a very low radar return and very dark images. However, when there is surrounding or emergent vegetation, wind, turbulence etc., there can be significant backscatter, which affects the accuracy of information obtained from the radar measurements (Smith, 1997).

Satellite remote sensing has been applied in hydrology for many years. Table 1 shows some satellite missions and sensors used for hydrological studies and the application areas. A review by Smith (1997) shows that the earliest hydrological applications were in water body and flood mapping; the review includes many examples of inundation maps developed from satellite imagery. Owe et al. (2001) also compiled papers presented at a conference on applications of remote sensing in many aspects of hydrology. Beyond mapping, satellite data in the form of imagery, a digital eleva-

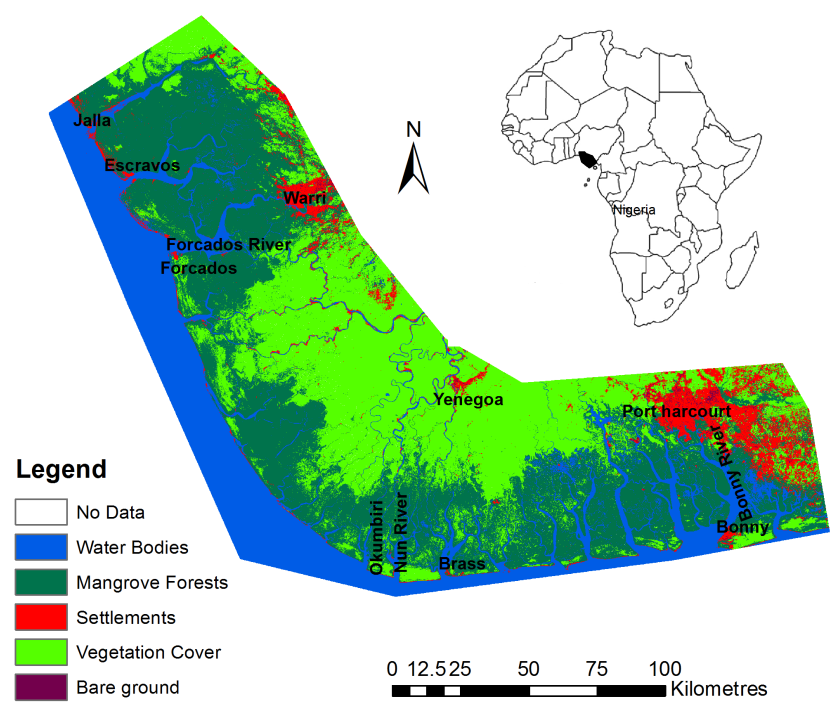

Figure 2. Classified NigeriaSat-1 image of the Niger delta showing five feature classes.

tion model (DEM), altimetry data, etc., can be used as hydraulic model input forcing factors or to constrain model data during calibration/validation/verification (Pereira-Cardenal et al., 2011). Satellite-based estimates of river flow, river width, water levels and flooding extent are used for model calibration/validation/verification. The choice of suitable observed data can introduce subjectivity into the modelling process and subsequently increase uncertainty. Consequently, satellite data used to benchmark the model output accuracy can influence model calibration and validation (Stephens et al., 2012). A review of types of satellite data used for flood modelling by Yan et al. (2015) discusses satellite data accuracy and methods used for error reduction.

The main scope of this review is to present literature findings about application of satellite remote sensing in surface water modelling, mapping and parameter estimation. The review limits itself to water flowing within channels and coastal areas, and therefore excludes applications of satellite remote sensing for soil moisture measurement, rainfall estimation, rainfall/runoff modelling, and its associated routing estimations.

The paper is structured into two main parts. The first gives an overview of applications of SAR, optical, altimetry and DEM data for estimation of surface water parameters, modelling and mapping. The second part discusses the limitations of utilizing satellite-derived data in surface water applications and the future directions aimed to fill the gaps. The review ends with a conclusion. 
Table 1. Some satellite missions and sensors used for hydrological studies.

\begin{tabular}{|c|c|c|}
\hline Mission & Sensor(s) & Application (hydrological) \\
\hline Aqua & $\begin{array}{l}\text { AIRS, AMSR-E, AMSU-A, } \\
\text { CERES, HiRDLS, HSB, MODIS }\end{array}$ & $\begin{array}{l}\text { Surface temperatures of land } \\
\text { and ocean (flood mapping) }\end{array}$ \\
\hline CryoSat & $\begin{array}{l}\text { DORIS-NG, laser reflectors } \\
\text { (ESA), SIRAL }\end{array}$ & $\begin{array}{l}\text { Ice thickness (applied also } \\
\text { for near-shore mapping and } \\
\text { inland water monitoring) }\end{array}$ \\
\hline Envisat & $\begin{array}{l}\text { AATSR, ASAR, ASAR } \\
\text { (image mode), ASAR } \\
\text { (wave mode), DORIS-NG, } \\
\text { MERIS, MIPAS }\end{array}$ & $\begin{array}{l}\text { Physical oceanography, ice } \\
\text { and snow (ocean/river water } \\
\text { level altimetry) }\end{array}$ \\
\hline ERS1 & $\begin{array}{l}\text { AMI/SAR/image, } \\
\text { AMI/SAR/wave, }\end{array}$ & $\begin{array}{l}\text { Earth resources, physical } \\
\text { oceanography (altimetry) }\end{array}$ \\
\hline ERS2 & $\begin{array}{l}\text { AMI/scatterometer, ATSR } \\
\text { AMI/SAR/image,AMI/SAR/wave, } \\
\text { AMI/scatterometer, ATSR/M }\end{array}$ & $\begin{array}{l}\text { Earth resources, physical } \\
\text { oceanography (altimetry) }\end{array}$ \\
\hline Jason1 & $\begin{array}{l}\text { DORIS-NG, JMR, LRA, } \\
\text { POSEIDON-2 (SSALT-2), TRSR }\end{array}$ & $\begin{array}{l}\text { Physical oceanography (ocean/ } \\
\text { river water level altimetry) }\end{array}$ \\
\hline Jason2 & $\begin{array}{l}\text { AMR, DORIS-NG, GPSP, JMR, } \\
\text { LRA, POSEIDON-3 }\end{array}$ & $\begin{array}{l}\text { Physical oceanography } \\
\text { (altimetry) }\end{array}$ \\
\hline Radarsat $1 / 2$ & C-band SAR, X-band SAR & Flood mapping/modelling \\
\hline Sentinel 1 & C-band SAR & Flood mapping/modelling \\
\hline SRTM & C-band SAR, X-band SAR & $\begin{array}{l}\text { Digital elevation models, } \\
\text { flood modelling }\end{array}$ \\
\hline SPOT 4 & $\begin{array}{l}\text { DORIS (SPOT), } \\
\text { HRVIR, VEGETATION }\end{array}$ & $\begin{array}{l}\text { Digital terrain models, } \\
\text { environmental monitoring }\end{array}$ \\
\hline SPOT 5 & $\begin{array}{l}\text { DORIS-NG (SPOT), HRG, } \\
\text { HRS, VEGETATION }\end{array}$ & $\begin{array}{l}\text { Digital terrain models, } \\
\text { environmental monitoring }\end{array}$ \\
\hline Terra & $\begin{array}{l}\text { MODIS, MOPITT, MISR, } \\
\text { ASTER, CERES }\end{array}$ & $\begin{array}{l}\text { Physical processes, surface } \\
\text { temperatures of land and } \\
\text { ocean (surface water mapping) }\end{array}$ \\
\hline Topex/Poseidon & $\begin{array}{l}\text { DORIS, LRA, POSEIDON-1 } \\
\text { (SSALT-1), TMR, TOPEX }\end{array}$ & $\begin{array}{l}\text { Physical oceanography } \\
\text { (altimetry) }\end{array}$ \\
\hline
\end{tabular}

\section{Overview of satellite data applications for surface water studies}

\subsection{SAR data applications}

SAR data are useful for flood extent measurements even in cloud-covered areas, and are therefore often used to make flood maps (e.g. Schumann et al., 2007; Horritt, 2006; Di Baldassarre et al., 2009; Vermeulen et al., 2005; Mason et al., 2007; Long et al., 2014). The variation of radar backscatter from different targets enables flood extent mapping. Several methods have been used to delineate the flooding extent from SAR data; e.g. utilization of multi-polarized advanced SAR images, application of a statistical active control model, multi-temporal image enhancement and differencing, histogram thresholding/clustering, radiometric thresholding, pixel-based segmentation, and use of artificial neural networks (Long et al., 2014). Multi-temporal image flood mapping involves acquiring flooding and non-flood images of the same area and combing them to get an image which indicates change by colours appearing in the image. A modification of the multi-temporal technique introduces an index that shows the changing areas (Skakun, 2010). Sarhadi et al. (2012) applied satellite stereoscopic images of Cartosat-1 to delineate flood hazard maps; the method used rational polynomial coefficients to extract a high-resolution digital terrain model (DTM) and detailed parameterization of the channel in the Halil Rud basin and Jiroft in south-eastern Iran. 
Segmentation threshold algorithms are used to delineate flood extents after a threshold has been manually chosen. Flood extent maps were created over 4 years of seasonal flooding in the Chobe floodplain, Namibia (Long et al., 2014). Eleven scenes of SAR data were enhanced using adaptive Gamma filtering (to remove speckles) and difference images created by subtracting from the reference nonflood season image. The histograms of the difference images were then used to create thresholds separating flooded and non-flooded areas. The threshold for flooded areas was determined by subtracting the standard deviation multiplied by a coefficient $K_{\mathrm{f}}$ from the mean pixel value. For flooding under vegetated areas, the threshold was determined by adding the standard deviation multiplied by a coefficient $K_{\mathrm{fv}}$ to the mean pixel value. The flood maps were then created using segmentation clustering in ENVI. Segmentation based on self-organizing Kohonen map (SOM) neural networks was used by Skakun (2010) to map flooding from five rivers in China, India, Hungary, Ukraine, Laos and Thailand. Training and testing of the neural networks were based on groundtruth data which enabled classification of water and dry land pixels. SOM produces a low-dimensional representation of the input space that still preserves the topological properties of the input space. The method enabled automatic discovery of statistically salient features of pattern vectors, clustering and classification of new patterns. The resulting flood maps show an 85-95\% classification rate compared with independent testing data, showing the applicability of the method for emergency flood mapping.

The interferometric phase difference between two SAR images is called the interferogram and includes signatures from topography, noise, displacement, atmospheric effects and baseline error. The advantage of phase changes in interferometer SAR (InSAR) data enables detection of changes in the Earth's land use and land cover. This characteristic is very useful for identification of flooded areas over wetlands as used by Dellepiane et al. (2004). The method, based on fuzzy connectivity concepts, automatically selected the coastline from two InSAR images using the coherence of the two images.

InSAR has been used to calculate the changes in water levels using satellite altimetry data for calibration (Kim et al., 2009; Jung et al., 2010). To obtain the displacement phase used to obtain the change in water height, all other signals are removed. The interferogram data give the relative water level change between two locations. Where there is measured water level data (within an acceptable radius), the relative water level change can be converted into the absolute water level change. Jung el al. (2010) used interferometric SAR data from JERS-1 to study change in water levels for the Amazon and Congo rivers. The data were acquired for the low-flow and high-flow seasons and processed using the "two pass" method which includes flat Earth phase removal and interferometric phase removal. Flooded vegetation, non-flooded areas and open water were differentiated based on backscatter "noise floor" and "mean interferometric coherence" of flooded and non-flooded areas. The temporal variation in water level $\mathrm{d} h / \mathrm{d} t$ was obtained by converting the phase changes in imagery to water level referenced to the WGS84 datum using altimeter measurements from Topex/Poseidon. Using $\mathrm{d} h / \mathrm{d} t$ to characterize the Amazon floodplain showed increasing $\mathrm{d} h / \mathrm{d} t$ from upstream to downstream within a complex pattern of interconnected channels with distinct boundaries and varying $\mathrm{d} h / \mathrm{d} t$. The Congo River characterization of $\mathrm{d} h / \mathrm{d} t$ showed a uniformity and limited connectivity between the river and the adjoining wetlands. Schumann et al. (2007) used Envisat ASAR data to identify spatial clusters of channel roughness in order to calibrate a HEC-RAS model of Alzette River flooding. ERS SAR data of the same event and an aerial photo of an earlier event were used for validation of the calibrated model and overall model performance was compared to measured high water marks at seven points during the flood event. The mean cross-sectional water levels used for model evaluation were estimated from the intersection of ASAR flood extent boundaries with a lidar DEM. At each cross section, ranges of channel roughness values are run in a Monte Carlo simulation and the cumulative distribution functions (CDFs) of the values are generated; these CDFs are compared with a CDF of a uniformly distributed model (where model functioning is the same over the entire parameter space). The deviation of the individual CDFs from the CDF of uniform distribution gives the measure of the parameter sensitivity, the sum of which shows the local functioning of the model at that cross section. CDFs with similar error characteristics are grouped into clusters using $k$-mean clustering. The results showed that two clusters of roughness values are enough to measure the parameter sensitivity.

To utilize SAR data for flood depth estimation, methods have been developed that derive flood heights from flood extent data. The methods used combine SAR data with elevation data sources like DEMs, altimetry, and triangular irregular networks (TINs). Mason et al. (2007) and Schumann et al. (2006) estimated the mean cross-sectional water levels used for model evaluation from the intersection of SAR flood extent boundaries with a lidar DEM. Schumann et al. (2006) used linear regression and an elevation-based model (REFIX) to convert SAR flood extent to heights and derived the flood water depth. Assuming a horizontal water height at cross sections, the water levels on the left and right banks were taken and used to subtract the floodplain DEM values to get the water height. The flood water line was then extracted using the regression equation: $H=a \cdot d+b$, where $a=$ slope of the regression line, $d=$ downstream water distance, and $b=$ intercept. Using the cross sections as break lines and the flood water heights extracted, a TIN of the water heights at each cross section was produced. The flood water depth was derived by subtracting the DEM at the crosssectional interception points from the flood water height TIN. The result showed an RMSE of $18 \mathrm{~cm}$ for a channel with 
no hydraulic structures and $31 \mathrm{~cm}$ for a channel with many hydraulic structures and changes in slope. The study recommends that nonlinear regression/piece-wise regression can be used in the case of sudden changes in slope (due to hydraulic structures) that cause the channel geometry to change.

Altimetry data from ENVISAT were combined with InSAR data from PALSAR and Radarsat-1 to compute absolute water level changes over the wetlands of Louisiana (Kim et al., 2009). The two-pass InSAR method was used to check the two SAR images acquired at different times for phase differences. The ENVISAT altimetry data were used as the reference absolute water level change $\mathrm{d} h_{0} / \mathrm{d} t$ to compute the all the changes in water level over the domain. The results obtained for water level changes showed better comparison with the wetland gauge than with the channel gauge, which had many levees interrupting the flow. Westahoff et al. (2010) mapped probabilistic flood extents from SAR data by using the amount of backscatter and local incidence angles to create histograms that distinguish between wet and dry areas. The histograms were used to calculate the probability of flooding of every pixel.

Satellite data are used to calibrate hydrologic models, especially in un-gauged catchments (Vermeulen et al., 2005; Sun et al., 2009). Calibration of flood inundation models can be done using several model parameters, but the most sensitive parameter that shows a direct relationship with water stage and therefore flooding extent and timing is the channel roughness (Schumann et al., 2007). Woldemicheal et al. (2010) showed that for braided rivers where the hydraulic radius is obtained from indirect sources like satellite data, Manning's roughness coefficients can be used to minimize computed water level outliers. Roughness coefficient values to be used for calibration can be determined via flood modelling where the measured data are available.

Satellite-based maps of flood extent have been used to calibrate flood inundation models either based on single or multiple flood events (Di Baldassarre et al., 2009). Horritt (2006) calibrated and validated a model of uncertain flood inundation extent for the Severn River using observed flooded extent mapped from satellite imagery. Model accuracy was checked using reliability diagrams, and model precision was checked using an entropy-like measure which computes the level of uncertainty in the flood inundation map. The ensemble model outputs were compared with ERS and Radarsat data for calibration using the measure of fit. The results showed that the mapped flood extent produced only a modest reduction in the uncertainty of model predictions because the timing of satellite passes did not coincide with the flood event. Di Baldassarre et al. (2009) showed that satellite flood imagery acquired during an event can be reliable for flood mapping. They used imagery of a single event covered by two satellite passes captured almost at the same time to develop a method to calibrate flood inundation models based on "possible" inundation extents from the two imageries. Hydrodynamic flood model extents were compared with the satellite flood extent maps in order to calibrate the floodplain frictional parameters and determine the best satellite resolution for flood extent mapping. In spite of their different resolutions the result showed that both satellite imageries could be used for model calibration, but different frictional values have to be used in the model.

For un-gauged basins where hydrological data are inaccessible, satellite measurement of river width can be used for hydrological model calibration (Schumann et al., 2013; Sun et al., 2009). River width can be estimated from several sources of satellite data, making it more readily available than discharge or water level. Sun et al. (2009) used measured river width from satellite SAR imagery to calibrate HYMOD hydrological model. The model calibration based on river width gave an $88.24 \%$ Nash coefficient, with a larger error during low-flow than high-flow periods, implying its usefulness for flood discharge calculations. From the results, braided rivers showed lower errors for good $Q-W$ relations from satellites. However, a small error in width measurement can lead to a large error in discharge estimation as the discharge variability was much larger than the width variability. Sun et al. (2010) used the GLUE methodology to reduce this uncertainty in calibration of river width-to-discharge estimation with the HYMOD hydrological model. From 50000 samples of the parameter sets, 151 (likelihood equals RMSE values) succeeded as behavioural sets to be used in the model to simulate the measured satellite river widths. River discharge simulated with the successful parameters (likelihood equals Nash-Sutcliffe efficiency) gave good discharge simulation with a correlation $R^{2}=0.92$.

Model use in forecasting is affected by the propagation of the input uncertainties which make it less accurate. Data assimilation can be used to reduce the accumulation of errors in hydraulic models. Assimilation combines model predictions with observations and quantifies the errors between them in order to determine the optimal model and improve future forecasts (Mcmillan et al., 2013). Types of assimilation techniques include Kalman filter (and its variations), particle filter and variational technique. Particle filter assimilation is a Bayesian learning system which accounts for input data uncertainty propagation by selecting suitable input data from randomly generated ones without assuming any particular distribution of their PDF (Noh et al., 2011). The particle filter technique was used in studies like Matgen et al. (2010) and Giustarini et al. (2011), where input data are in the form of ensemble flow outputs of a hydrological model. In Giustarini et al. (2011) to assimilate water levels derived from two SAR images of flooding in the Alzette River into a hydraulic model, 64 upstream flows were generated from an ensemble hydrologic model and used as the upstream boundary conditions. The most commonly used data assimilation technique however is the Kalman filter, which is a state-space filtering method which assumes a Gaussian distribution of errors. Vermeulen et al. (2005) used SAR-derived flood maps and time series data to make flood forecasting more accurate 
through data assimilation. The assimilation process based on the Kalman filtering technique used adaptation factors to multiply the original model output and an adaptation factor in order to generate a new parameter value. The process included calculation of water levels/discharge on the Rhine River by combining hydrologic modelling of the sub-basins and hydraulic modelling using downstream measured data. Data assimilation was done using measured water levels to determine the roughness coefficients which calibrate the calculated water levels. The model output water levels were compared with water levels derived from flood maps but because the natural flow of the channel or floodplain has been modified, good results were only obtained when the georeferencing of the map is deliberately shifted or the flooding extent is exaggerated by adding some random noise over a large area of 7-12 km. Barneveld et al. (2008) applied the same method and models for flood forecasting on the Rhine River and produced good results of 10-day forecasts; therefore assimilating data for natural catchments results in better forecast model values. More information on hydrologic data assimilation techniques can be found in Matgen et al. (2010), Chen et al. (2013) and García-Pintado et al. (2015).

\subsection{Satellite altimetry data applications}

Satellite altimetry (Fig. 3) works on the principle of return echo of pulses sent from the satellite nadir point and reflected from the surfaces of open water.

The height of the water surface is extracted from the distance between the satellite and the water body with reference to a local datum given as

$h=R-\left(c \frac{\Delta t}{2}\right)-\sum$ cor

where $h$ is water level, $R$ is the distance between the satellite altimeter and the water body, $c$ is the speed of light, $\Delta t / 2$ is two-way travel time of radar pulse, and $\sum$ cor is the sum of corrections for ionospheric, wet and dry tropospheric, and tidal corrections.

This principle (Fig. 3) has its limitations as the accuracy of the data is affected by atmospheric conditions, sensor and satellite characteristics, and reflectance conditions (Belaud et al., 2010).

Although satellite altimetry was developed and optimized to measure ocean level changes (not rivers), it has been demonstrated as a source of data over large rivers and lakes (Tarpanelli et al., 2013; Jarihani et al., 2013). Typical altimeter footprints are in kilometres; e.g. ENVISAT ranges from 1.6 to $10.8 \mathrm{~km}$, TOPEX/POSEIDON from 2.0 to $16.4 \mathrm{~km}$. Thus satellite altimetry data are used as the primary source of water level data in ungauged basins, and as a secondary data source to compare with measured data in sparsely gauged basins.

Oftentimes the selection of altimeter water level data to be used depends on the time and season of acquisition (Papa

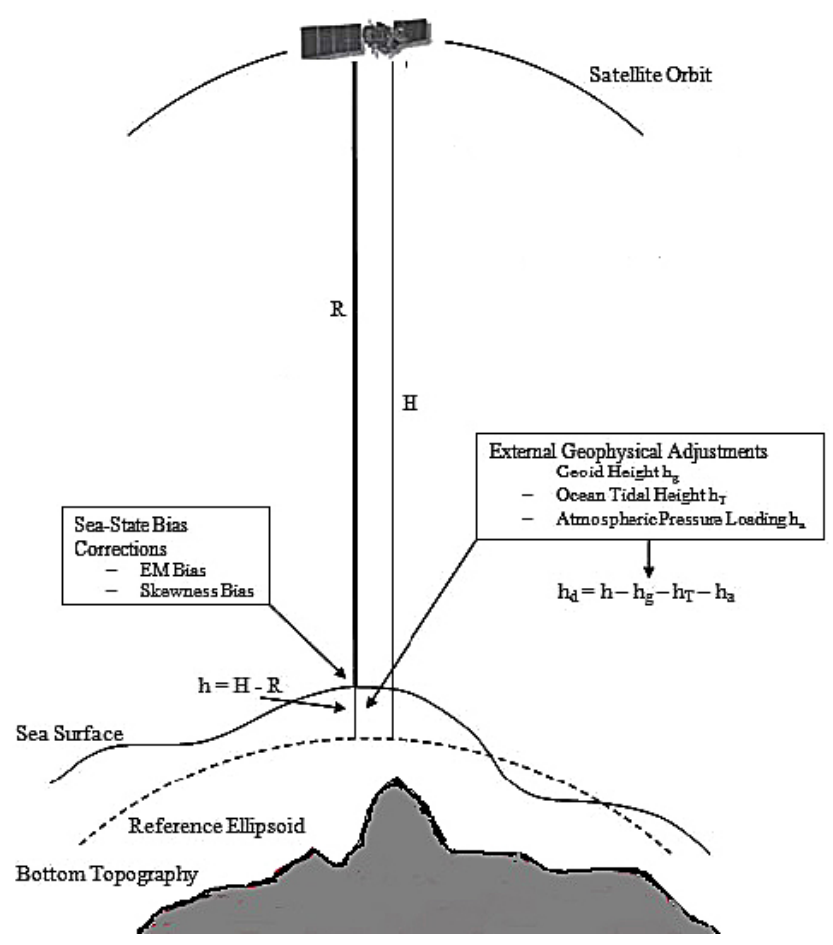

Figure 3. An illustration of height measurement using satellite altimetry.

et al., 2012). Data acquired during high flows give better measurements than low-flow season data which usually have artefacts (in the form of islets, river banks, vegetation, etc.) that reduce the accuracy of the data in comparison with local gauge data. Analysing data over the Ganga-Brahmaputra rivers, Papa et al. (2012) got mean errors less than $20 \mathrm{~cm}$ when high-flow altimetry data were compared with measured data, but low-flow data showed errors larger than $30 \mathrm{~cm}$. Siddique-E-Akbor et al. (2011) used data from ENVISAT to compare with 1-D HECRAS model output water levels in order to check for accuracy and ability to get the seasonal trend. The model was run for periods of available ENVISAT data and the output compared with the ENVISAT time series. The results showed RMSE ranging from 0.70 to $2.4 \mathrm{~m}$, with the best correlation obtained during high-flow seasons. The study suggests the use of calibrated hydrodynamic/hydrologic model outputs to benchmark altimetry data in ungauged and poorly gauged catchments.

Virtual altimeter gauging stations are located at the intersection of satellite tracts with water bodies. Santos da Silver et al. (2007) used virtual altimeter stations as water level data sources for ungauged catchments. They chose the median values of virtual stations that fell within river water bodies as water levels for the river and compared with measured values from gauging stations located within $20 \mathrm{~km}$ of the virtual stations using weighted linear regression. In order to avoid comparing two areas with different hydrological conditions, a ratio $\chi$ was computed of the discrepancy between the EN- 
VISAT master points and the linear regression and the uncertainties associated with the ENVISAT master points. The developed method enabled a comparison that produced regression coefficient greater than 0.95 between the ENVISAT and gauges series. Santos da Silver et al. (2012) used 533 ENVISAT virtual stations and 106 gauging data to map extreme stage variations along 32 Amazon basin rivers and analysed for drought in the catchment. Using 2005 drought and 2009 flooding events as a basis, data from 2002 to 2005 were analysed and time series of ENVISAT per virtual station were averaged to get monthly values. Values of the mean amplitude stage variation for the measured gauges showed good consistency with those of satellite altimetry and results for drought showed a range between -4 and $1 \mathrm{~m}$ of anomalies. Getirana et al. (2009) went even further and developed a rating curve of discharge values using virtual stations from ENVISAT for the upper part of the Branco River basin, Brazil. Virtual station data were compared with nearby gauge data to check for seasonal similarity and trend, and those virtual stations with standard deviations $<0.1 \mathrm{~m}$ were chosen. The method used a distributed hydrological model to derive discharge values for the virtual stations. Model calibration and validation results showed good correlation with measured data, and the rating curve showed a $2.5-5 \%$ increase in bias when compared with rating curves from measured data. The calibration results were affected by rainfall data spatial distribution.

Although use of satellite altimetry for river stage monitoring is usually applied to large rivers with a few kilometres' width (Papa et al., 2012), altimetry data were used to estimate discharge in an ungauged part of the Po River basin (width: 200-300 m) using cross-sectional data (Tarpanelli et al., 2013). They used a simplified routing model (RCM) based on upstream data, wave travel time and hydraulic conditions on two river sections to get the flow in the second river section. The results showed good agreement between simulated and in situ discharges, and gave lower RMSEs (relative to the mean observed discharge) than calculated results using an empirical equation also based on cross-sectional geometry. Seyler et al. (2009) used altimetry virtual stations to estimate river slope. The calculated river slopes were used to get the river bank full discharge, and the results compared well with gauge data. Lake water volumes were calculated for Lake Mead (USA) and Lake Tana (Ethiopia) using five altimetry data products: T/P (Topex/Poseidon), Jason-1, Jason-2, GFO (Geosat Fellow On), ICESat and ENVISAT (Duan and Bastiaanssen, 2013). The method used Landsat TM/ETM + imagery data to map the water surface areas using the Modified Normalized Difference Water Index (MNDWI) method which enables robust extraction of water bodies from optical data (Zhang et al., 2006). The calculated water surface areas agreed with in situ measured data, with an $R^{2}$ of 0.99 for Lake Mead and 0.89 for Lake Tana, and with RMSEs of $2.19 \%$ for Lake Mead and $4.64 \%$ for Lake Tana. The water volume was estimated using the lowest altimeter water level as the reference water level; this is then subtracted from all the other measurements to obtain the water level above lowest level (WLALL) to be used for volume estimation. Using regression analysis a relationship was established between the estimated water surface areas and the $\mathrm{WLALL}$ as $A=f(\mathrm{WLALL})=a \mathrm{WLALL} 2+b \mathrm{WLALL}+c$; where $a, b$, and $c$, are constants. The integral of this relation provides the water volume above the lowest water level (WVALL). The estimated water volumes agreed well with in situ water volumes for both Lake Mead and Lake Tana with $R^{2}>0.95$ and RMSE ranging between 4.6 and $13.1 \%$.

\subsection{Optical satellite data}

Depending on its contents, water reflects electromagnetic waves differently; pure clear water reflects differently from muddy water or water containing vegetation (floating or submerged). The amount of energy measured from the satellite sensor also depends on the bands used; the blue band penetrates water up to $10 \mathrm{~m}$, the red band is partially absorbed, and the near-infrared band is totally absorbed. These sensor properties consequently affect the image, so that an image acquired using the blue band will measure reflectance from any submerged vegetation within its reach, while red/nearinfrared images will show water as dark grey/black, respectively (Meijerink et al., 2007).

With the availability of more optical satellites with relatively low temporal resolutions globally, many scenes of archived data can be accessed and used for change detection studies and flood extent mapping in areas with little cloud cover. Penton and Overton (2007) combined flood mask extents from LandSat ETM of four flood events with a lidar DEM to produce water heights for the floodplain. The heights of the flood mask water points were used to interpolate a water height surface which was subtracted from the DEM to produce the inundation map. To check for water surface change, satellite microwave data from the AMSR-E satellite were used to calibrate the CREST hydrologic model using ratio brightness temperature measurements over water bodies and calibrated dry areas (Khan et al., 2012). The AMSRE detected water surface signal frequency was compared with gauge flow with a probability of exceedance $<25 \%$ and showed good agreement. The output of model calibrated with AMSR-E detected water surface signal showed good agreement with observed flow frequency. Results of validation were equally good with high correlation between model results and observed flows with probability of exceedance $<25 \%$. The output of the model calibrated with AMSR-E detected water surface signal showed good agreement with observed flow frequency (Nash-Sutcliffe coefficient of 0.90 and a correlation coefficient of 0.80 ).

Due to inaccessibility of the coastal terrain, many remote wetlands and swamps have few or no gauges, and are not covered by national gridding systems. As a result, such areas are not included in topographic mapping projects; even 
where data are available, the resolution is usually very coarse and not detailed (e.g. in Ezer and Liu, 2010). The morphology of coastal areas is affected by sediment supply, sea level change, littoral transport, storm surges, as well as hydrodynamics at the river mouths of deltaic areas (Kumar et al., 2010). Tidal flat morphology, for example, changes with the tidal cycle, and this can affect navigation, coastal defence, fishing, etc. The monitoring and modelling of tidal flat morphology is thus important (Mason et al., 2010). Apart from natural causes, coastal areas are affected by human activities like sand mining, and construction of coastal infrastructure like ports, harbours, groins and other coastal defence systems.

Satellite data are used to study coastal morphological changes that affect the ecosystem and biodiversity of coastal areas. Kumar et al. (2010) studied the morphological changes in coastal parts of Karnataka State, India, using satellite and ancillary data. They calculated the rate of shoreline change over a 95-year period (1910-2005) and used the results to predict future shoreline change rates to 2029. Twentyfive LandSat TM imageries were used to map the tidal mudflats of Cooks Inlet, Alaska, by integrating with an inundation model (Ezer and Liu, 2010). The morphology of Cooks Inlet is such that tidal floods move much faster than the ebbing period which moves very slowly; therefore areas at the far end of the mudflats take several hours before tidal waters lower. To study their morphology as a test bed for prediction of floods and its effects, mapping of these frequently flooded areas was done using the LandSat imagery to delineate water-only areas, and show the range of shoreline data and water levels. The model results calculated the water depth and gave the estimated 3-D topography of Cooks Inlet. Similarly, four LandSat TM images of the GangesBrahmaputra River mouth taken during low-flow and highflow seasons were used by Islam et al. (2002) to estimate suspended sediment concentration. The method used converted the digital numbers of the imageries to radiance values and subsequently to spectral reflectance and linearly related them to suspended sediment concentration (SSC). The SSC results showed a higher distribution of suspended sediments during high-discharge seasons when the turbidity zone moves further seaward, reaching depths of $10 \mathrm{~m}$, than during low-flow periods when the turbidity zone remains close to the shore. Yang and Ouchic (2012) used 2000-2009 optical and SAR satellite imagery and in situ data of the Han estuary in South Korea to study bar morphology by relating it to tides and precipitation using regression analysis. The results showed areas closer to the sea correlating bar size/shape with tides, and areas closer to the river mouths correlating with precipitation.

Optical satellite images of Sumatra were used to study post-tsunami coastal recovery based on beach nourishment and sediment refilling. Liew et al. (2010) used $1 \mathrm{~m}$ Ikonos images of pre-tsunami, tsunami, and post-tsunami periods to show that coasts affected by tsunamis naturally rebuild to their former morphological states in areas with little anthro- pogenic activity. The results showed straight beaches rebuilding a few weeks after the tsunami, but recovery of barrier beaches and lagoons is much slower, enabling inland rivers and streams to directly discharge into the ocean. Thus, they concluded that due to the fast recovery of coastal features post tsunami, sedimentary deposits are better indicators of coastal geomorphology than tsunami events.

\subsection{Satellite-derived DEM data applications}

Satellite data provide topographic information in the form of digital elevation models (DEMs) generated from radar echoes of spot heights, e.g. ASTER DEM, SRTM, and SPOT DEM. The most common and freely available DEM is the Shuttle Radar Topographic Mission (SRTM) DEM flown in February 2000 which covered $85 \%$ of the Earth's surface. SRTM which was obtained through SAR interferometry of C-band signals is available in 30 and $90 \mathrm{~m}$ spatial resolutions and an approximate vertical accuracy of $3.7 \mathrm{~m}$ (Syvitski et al., 2012). The vertical accuracy of SRTM is higher in areas with gentle slopes than on steep slopes; on low-lying floodplains SRTM has shown less than $2 \mathrm{~m}$ accuracy. More information on SRTM DEM accuracy can be found in Yan et al. (2015) and Jarihani et al. (2015).

At the land-water boundary in areas with gentle slopes, satellite DEMs can be used to measure river stage when combined with high-resolution imagery. Such combinations have been used in flood inundation mapping, although there is less accuracy in situations where the water edge is obscured by vegetation (Smith, 1997). Syvitski et al. (2012) adjusted SRTM data using ocean heights measured by the TOPEX/POSEIDON satellite altimeter to enable the mapping of floodplain zones. Advanced microwave Scanning Radiometer (AMSR-E) data provided brightness temperature measurements of the floodplain. The ratio of land area brightness temperatures to water area brightness temperature gave the discharge estimator; chosen dry areas were used as calibration areas for measurements over water-covered areas. A rating curve of the ratio versus discharge was then used to extract the discharge values. Four floodplain zones were classified around the world from the 33 floodplains studied, namely, container valleys, floodplain depressions, nodal avulsions and delta plains. SRTM data measure surface level which over river channels is equivalent to water levels when the land water boundary is delineated. Jung et al. (2010) used in situ (bathymetry and cross-sectional) data and SRTM DEM water levels to derive water surface slope and to calculate the discharge of the Brahmaputra River. The crosssectional water level was obtained by fitting a first-degree polynomial function to the SRTM data elevation. The average calculated discharge results when compared to in situ gauge reading gave a difference of $2.3 \%$. Two DEMs of Morecambe Bay were used to determine the relative change in inter-tidal sediment volume above and below mean sea level (Mason et al., 2010). The first set of DEMs was de- 
rived from satellite SAR imagery and the second set from lidar. By using the sea height as zero level the lidar DEM was normalized to the same height as the SAR DEM. The relative change in sediment volume was derived by subtracting the normalized lidar DEM heights from the SAR DEM. SRTM $30 \mathrm{~m}$ data were combined with MODIS $500 \mathrm{~m}$ water mask data to produce $30 \mathrm{~m}$ static water masks of 2003 flooding along the Mississippi River (Li et al., 2013). The method involved using SRTM to mark the minimum water level from the MODIS water mask, which is then used to calculate the maximum water level for that pixel using a water fraction relation. All SRTM $30 \mathrm{~m}$ pixels with heights between minimum and maximum water levels are classified as water, and all those with heights higher than the maximum level are classified as dry. Consequently, the $500 \mathrm{~m}$ MODIS water mask is integrated into a $30 \mathrm{~m}$ water mask with the SRTM. The results gave detailed flood maps with the same flooding coverage as the MODIS water masks but enlarged 18 times. The flood maps were compared with Landsat TM images of the flood and showed over $94 \%$ match in water area coverage. Errors/mismatch were found to be mostly around areas with trees and vegetation cover.

\section{Future needs and direction}

\subsection{Gaps and limitations}

As useful as satellite data applications have been in estimating surface water parameters, the measurements come with limitations due to sensor specifications/errors, pre- and postdata processing techniques, calibration, measurement conditions, satellite distance from the targets, etc. Optical satellite data for example are limited to daytime acquisition due to their dependence on sunlight, and are not very useful in areas perpetually covered by clouds because the target cannot be reached (Smith, 1997).

Since satellite data are used for calibration, their accuracy when compared with measured data is very important. Satellite data accuracy is estimated using different error measurement techniques (e.g. RMSE, mean error), checking for correlation with measured data or measuring the coefficient of determination (e.g. Tarpanelli et al., 2013). There are multiple sources of error that can affect the data; for example, the uncertainties in using satellite river width for calibration include the satellite estimation of the river width, the power relation between the discharge and river width (which is an approximation of the conditions at a river cross section when there is no backwater effect) and the assumption of a stable/static river cross section. However, these sources of uncertainty are lowest for the period of satellite data acquisition, and increase with change in season and hydraulic conditions (Sun et al., 2010).

\subsubsection{SAR}

The quality and usefulness of SAR data for hydrological studies depend on meteorological conditions (wind and rain), emergent vegetation, incidence angle and the polarization mode used for data acquisition. Horizontal-horizontal $(\mathrm{HH})$ polarization gives better results for flood extent mapping than vertical-horizontal $(\mathrm{VH})$ and vertical-vertical (VV) polarizations. However, $\mathrm{VH}$ and VV polarizations are also useful since VV polarization data highlight vertical features like vegetation, and $\mathrm{VH}$ polarization data reflect the horizontal nature of the smoothed flood water (Schumann et al., 2007). Another important factor for SAR data use in hydrology is the river size. Until the recent launch of CSK, Radarsat-2, PALSAR, and TerraSAR-X, most available SAR satellites had large spatial resolutions which excluded smaller rivers from being captured, since it was difficult to delineate them in an image (Sun et al., 2009).

Satellite SAR used for delineation of water extent has the limitation of floodplain vegetation being included and classified as water pixels; moreover, the height of the SAR waterline does not show the variation in water height with flow direction.

\subsubsection{Altimetry}

For river stage estimation and wetlands delineation, problems encountered with satellite altimetry data include incorrect processing of radar echoes over rivers/lakes by satellite trackers, poor temporal resolution, and lack of information within the data about the atmospheric wet vapour content over lakes/rivers (Crétaux et al., 2009). The errors recorded while using altimeter water level data can however be increased by incorrect choice of data, which frequently occurs when dry area data are retained within the data for computing water stages in low-flow seasons (Santos da Silva et al., 2007). The difference between altimeter and gauge measurements also increases with distance between the points, topography and river width (León, et al., 2006). When compared with gauge data, RMSEs of altimetry data measured over the Amazon have ranges from 30 to $70 \mathrm{~cm}$ using data from ENVISAT, ERS2, and GeoSaT (Tarpanelli et al., 2013); however, at cross track situations where altimetry measurements are taken at the same location with a gauging station, the difference can be $<20 \mathrm{~cm}$ (Seyler et al., 2009). The accuracy of altimeter measurements over rivers is also affected by the river width and the morphology of the river banks so that data on narrow rivers and vegetated banks have lower accuracy (Papa et al., 2012). Furthermore, the specifications of the altimetry system itself can affect the quality of measurements; for example, ENVISAT data have been shown to have lower RMSE compared to ERS2 data due to ENVISAT's ability to switch frequency modes in response to changes in terrain and its smaller bin width (Tarpanelli et al., 2013). 


\subsubsection{DEM}

The limitation of a satellite DEM is in the data quality. DEM data needed for modelling and other analyses that require topographic data depend on the acquisition method, the data processing and the characteristics of the mapped terrain. Satellite-derived DEMs have less vertical accuracy, higher bias and higher RMSE than other DEMs derived from airborne lidar and airborne IFSAR (Fraser and Ravanbakhsh, 2011).

In spite of their limited accuracy satellite DEMs have global or almost global coverage unlike airborne DEMs. Therefore they are useful sources of topographic data, especially for low-lying coastal areas with gentle slopes (Gorokhovich and Voustianiouk, 2006; Schumann et al., 2008), and consequently applicable for inundation modelling (Karlsson and Arnberg, 2011). Figure 4 shows results of flood modelling undertaken for the lower Niger River (Nigeria) using SRTM 30 and $90 \mathrm{~m}$. The Niger River overflowed its banks in 2007 and flooded a large part of the floodplain. MODIS satellite data were used to map the flood and provided the only reference record of the flood. Figure 4 shows that the model results are comparable with the MODIS flooding extent.

Generally, satellite-based DEMs are either generated from radar echoes of spot heights or from SAR interferometry. However, Mason et al. (2010) also derived DEMs from SAR images. The method involved using SAR water height to interpolate a set of water lines, which were then used to produce a $50 \mathrm{~m}$ DEM of the intertidal zone with an accuracy of $40 \mathrm{~cm}$. The method is however limited by the temporal decorrelation of the waterline heights.

\subsection{Current data use strategies}

Innovative methodologies are being introduced by scientists to better exploit satellite data to overcome the data limitations within present uncertainties. For example cloud filtering techniques have been developed that remove a high percentage of the clouds in optical data, thus adding to data availability. In terms of temporal limitations, combining MODIS data with its high temporal resolution with other types of satellite data is a technique that is now exploited more (Jarihani et al., 2014). The technique generates new data sets that blend higher spatial resolution at the high temporal resolution of MODIS. When combined with DEM data, for example, flood maps that provide daily information can be easily generated ( $\mathrm{Li}$ et al., 2013). SRTM has been combined with MODIS data to generate a $250 \mathrm{~m}$ water mask called MOD44W; because of the high temporal resolution of MODIS this product can be updated regularly to provide static water masks (Li et al., 2013).

Use of satellite SAR for flood extent mapping and model calibration can be improved through combination with other higher-resolution data to increase precision in flood height

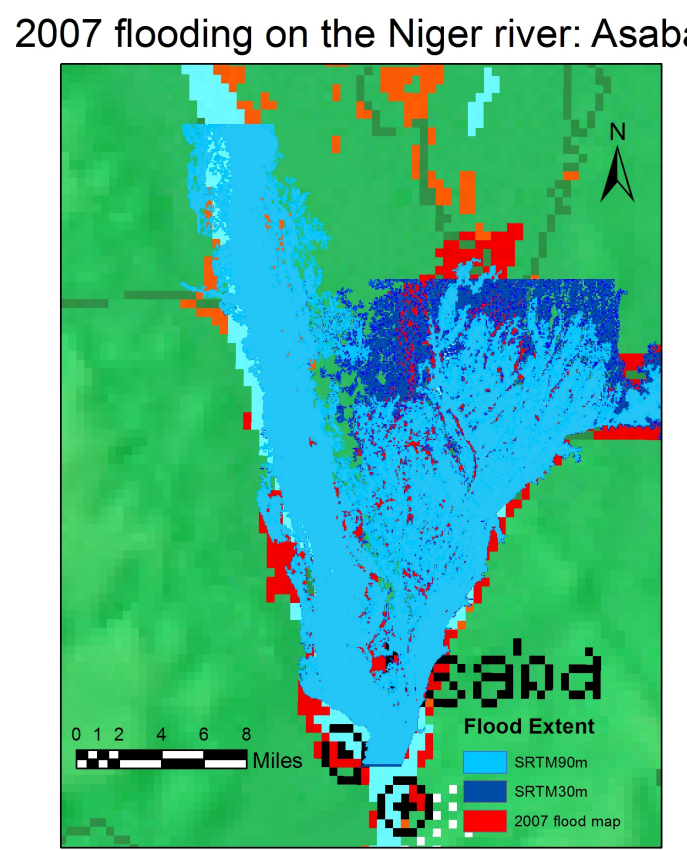

Figure 4. Model simulation result of flooding on the Niger River (2007) using SRTM topographic data.

determination. To improve the vertical accuracy of SAR waterline extent during floods, Mason et al. (2007) used waterline data extracted from ERS-1 SAR corrected with $1 \mathrm{~m}$ resolution lidar heights (along the Thames River bank) to calibrate a LISFLOOD model of flood extent. The output waterline when compared with waterline measured from aerial photos showed a lower root mean squared error than those obtained using SAR data only.

Satellite DEMs that are enhanced through vegetation smoothing or hydrological correction have shown lower errors compared with the original data (Jarihani et al., 2015). Due to the availability of the hydrologically corrected SRTM DEM, a global static $30 \mathrm{~m}$ water mask has been generated which is very useful for flood detection, especially in datascarce areas.

To improve the use of satellite altimetry data, interpolation methods have been developed to correct the data accuracy and precision by comparing the data with lakes and reservoir measurements. Thus the correlation with measured gauge data, range of RMSE and reduction in discrepancies have improved to levels $>0.95$ correlation during validation (Ričko et al., 2012). Altimeter measurements over modified channels is however less reliable than that of natural catchments (Kim et al., 2009).

The use of altimeter data is also limited by the poor temporal resolution of satellite altimeters; which range from days to several weeks. Belaud et al. (2010) developed a method to interpolate river water levels in-between satellite observations in order to provide continuous data. The developed method used upstream ground station measurements and altimetry 
data as output to calibrate a propagation model by adjusting the satellite observed values. The propagation model used a transfer function to predict water level variations based on the relationship between the propagation times and water levels. The results were able to predict flood peaks during periods of no satellite coverage. Crétaux et al. (2011) addressed the problem of data gaps by combining three sets of altimetry data (TOPEX/POSEIDON, ENVISAT1 and JASON2) with MODIS measurements of water extent to monitor wetlands and floodplains in arid/semi arid regions. The MODIS data were used to classify the open water pixels whose relative values were then extracted from altimetry data. The results provided relative water heights, due to the low temporal resolution of the altimetry data sets. Altimeter data from ICESat were used to calibrate a large-scale LISFLOOD-FP hydrodynamic flood model of the Zambezi River, Mozambique (Schumann et al., 2013). Eight in-channel water levels from ICESat from one altimeter pass were used for calibration of model output. The models with a mean bias within one standard deviation of the ICESat values were accepted as comparable with Landsat measured flooding extents. The results showed $86 \%$ agreement between the Landsat flood extent and the accepted model outputs, corresponding to a mean distance of $1.42-1.60 \mathrm{~km}$. After calibration the model upstream boundary was changed to forecast flow values in order to forecast downstream flooding. The results correlated with the baseline model, but showed that with a lead time of 5 days, better basin-wide precipitation observations will enable flood forecasting on the Zambezi.

\subsection{Future direction}

The available literature shows that efforts have been made to develop an empirical relationship between satellite-derived surface water extents (including flooded areas) with river stage or discharge. Such a relationship has been established for braided rivers; for non-braided rivers, the results have depended on the river system; thus, inundation area can increase or decrease with stage. With better SAR missions such as TerraSAR-X-TanDEM-X formation, DEM data with good vertical accuracy are now available for better hydraulic flood modelling. TanDEM-X has $12.5 \mathrm{~m}$ spatial resolution and produces less than $2 \mathrm{~m}$ vertical accuracy (DLR, 2015). Although made for polar ice change estimation and monitoring, the high spatial coverage of Cryosat-2 is also being exploited for near-shore mapping and inland water monitoring (Villladsen et al., 2014). Cryosat-2, which operates in SAR and interferometric modes, has a drifting orbit and therefore (unlike all the other satellites) has few repetitive data (since the repeat cycle is 369 days). Its high spatial density coverage makes it good for hydraulic modelling (and all its evaluations have produced good results). With successful use of Cryosat2 data to obtain river water levels and topography, the use of drifting orbits is being proposed as more suitable for river water surface topography mapping, derivation of river profiles and building of pseudo time series (Bercher et al., 2014).

Other satellite products that improve the accuracy of satellite data based research in hydrology include CosmoSkyMed from the Italian Space Agency, Radarsat-2 from the Canadian Space Agency, and Sentinel-1 from ESA (Schumann et al., 2015). Others are Global Change Observation Mission-Water (GCOM-W) from the Japan Space Agency (JAXA), Global Precipitation Measurement (GPM) from JAXA/USA, and Soil Moisture Active Passive (SMAP) from the USA.

To improve the quality of satellite SAR and topographic data, new satellite missions with higher-precision instruments are being planned. One such mission is the Sentinel constellation that will consist of seven satellites, two of which (Sentinel 3 and 6) are especially dedicated to hydrological purposes. Sentinel 1 is already in orbit and undergoing calibration; it has a C-band SAR instrument to continue present C-band data provision. Sentinel 3 is planned to provide fast data for flood emergencies; therefore, it has three instruments, one of which is a dual-frequency ( $\mathrm{Ku}$ - and $\mathrm{C}$ band) advanced synthetic aperture radar altimeter (SRAL) that will provide accurate topographic data of oceans, ice sheets, sea ice, rivers and lakes (ESA, 2015). Sentinel 6, which will compliment the Sentinel 3 data, will carry on board a high-precision radar altimeter. The Radarsat constellation, a new low Earth orbit (LEO) C-band SAR mission, is under development by the Canadian Space Agency (CSA). The constellation which will have several operating modes will provide interferometric SAR data that can be used for wetlands and coastal change mapping, flood disaster warning and response with resolutions 3, 5, 16, 30, 50 and $100 \mathrm{~m}$ (CSA, 2015).

Other upcoming satellite missions like Surface Water and Ocean Topography (SWOT) made especially to survey global surface water have specifications that will enable better use of satellite data in hydrology. SWOT, which uses a wide-swath altimetry technology, will also observe the fine details of the ocean's surface topography and measure how water bodies change over time with repeated high-resolution elevation measurements. The mission, scheduled to be launched in 2020, is an international collaboration between the US National Aeronautics and Space Agency (NASA) and Centre National Etudes Spatiales (CNES) of France, supported by the Canadian Space Agency (CSA) and the UK Space Agency (UKSA) (Pavelsky et al., 2015). Another product of international cooperation that will support hydrological research is the Jason3 altimetry mission from NOAA, due to be launched in July 2015. The Jason3 mission is dedicated to the measurement of sea surface height, waves, and wind speed, and will provide useful data to monitor sea level rise, coastal area modelling of oil spills, forecasting of hurricanes, etc. To enable precise detection of sea level change, Jason 3 combines GPS, radar altimetry, and a microwave radiometer to produce data within $1 \mathrm{~cm}$ accuracy every 10 days 
(NOAA, 2015). Jason3 is jointly owned by US National Oceanic and Atmospheric Administration (NOAA), CNESFrance, European Organisation for the Exploitation of Meteorological Satellites (EUMETSAT), and US NASA.

\section{Conclusions}

Satellite remote sensing provides a source of hydrological data that is unhindered by geopolitical boundaries, has access to remote/unreachable areas, and provides frequent and reliable data (Jung et al., 2010). Use of satellite data to estimate hydrological parameters continues to increase due to greater availability of satellite data, improvement in knowledge of and utilization of satellite data, as well as expansion of research topics. A very important catalyst for this growth in satellite data utilization is the ability to use it in a GIS environment. GIS enables comparison and deduction of relationships that exist amongst the complex data sources used for analysis. Thus relationships like the effects of land-use change on surrounding water bodies or water management are easily analysed and depicted. Consequently, satellite data are commonly used for mapping of water bodies, testing of inundation models, soil moisture measurements, precipitation monitoring, estimation of evapo-transpiration, and mapping of flood extent.

Data quality, pre-/post-data processing, etc., introduce new errors and increase the uncertainties in satellite data utilization. However, several methods have been developed to quantify the errors and produce acceptable results. Moreover, a number of satellite missions to address issues of climate change are being planned; some of these are dedicated to water resource management and will carry high-precision instruments. The products of these missions will have less error; consequently, results obtained will be more accurate, thereby filling the gap in data availability.

Author contributions. The authors worked together as a team in developing the review paper.

Acknowledgements. This review is part of a study being undertaken by the first author, and is sponsored by the National Space Research and Development Agency (NASRDA), Nigeria.

Edited by: H. Cloke

\section{References}

Barneveld, H., Silander, J., Sane, M., and Malnes, E.: Application of satellite data for improved flood forecasting and mapping, 4th International Symposium on Flood Defence: Managing Flood Risk, Reliability and Vulnerability, 6-8 May 2008 Toronto, Canada, retrieved from: http://www.hkv.nl/site/hkv/upload/publication/Application_ ofsatellite_data_forimprovedflood_forecastingHJB.pdf (last access: 1 June 2015), 2008.

Belaud, G., Cassan, L., and Bader, J. C.: Calibration of a propagation model in large river using satellite, 6th International Symposium on Environmental Hydraulics, Athens, Greece, 869-874, 2010.

Bercher, N., Calmant, S., Picot, N., Seyler, F., and Fleury, S.: Evaluation of Cryosat-2 measurements for the monitoring of large river water levels, retrieved from: Along-Track.com: http://chronos.altihydrolab.fr/2012-09-23_Venice_ESA_20_ years_of_progress_in_altimetry/Bercher.2012b_(Venice_Paper) _CryoSat-2_hydro.pdf (last access 25 June 2015), 2014.

Chen, H., Yang, D., Hong, Y., Gourley, J., and Zhang, Y.: Hydrological data assimilation with the Ensemble Square-Root-Filter: Use of streamflow observations to update model states for realtime flash flood forecasting, Adv. Water Resour., 59, 209-220, doi:10.1016/j.advwatres.2013.06.010, 2013.

Crétaux, J. F., Stéphane, C., Romanovski, V., Shabunin, A., Lyard, F., Bergé Nguyen, M., Cazenave, A., Fabrice, H., and Perosanz, F.: An absolute calibration site for radar altimeters in the continental domain: lake Issykkul in Central Asia, J. Geodesy, 83, 723-735, 2009.

Crétaux, J. F., Bergé-Nguyen, M., Leblanc, M., Del Rio, R. A., Delclaux, F., Mognard, N., Lion, C., Pandey, R. K., Tweed, S., Calmant, S., and Maisongrande, P.: Flood mapping inferred from remote sensing data, Fifteenth International Water Technology Conference, 28-30 May 2011, Alexandria, Egypt, 2011.

CSA - Canadian Space Agency:RADARSAT Constellation, retrieved from: RADARSAT constellation: http://www.asc-csa.gc. ca/eng/satellites/radarsat/, last access: 23 June 2015.

Dellepiane, S., de Laurentiis, R., and Giordano, F.: Coastline Extraction from SAR Images and a Method for the Evaluation of the Coastline Precision, Pattern Recog. Lett., 25, 1461-1470, 2004.

Di Baldassarre, G., Schumann, G., and Bates, P. D.: A technique for the calibration of hydraulic models using uncertain satellite observations of flood extent, J. Hydrol., 367, 276-282, doi:10.1016/j.jhydrol.2009.01.020, 2009.

DLR: Earth Observation: TanDEM-X - the Earth in three dimensions, retrieved from: http://www.dlr.de/dlr/en/desktopdefault. aspx/tabid-10378/566_read-426/\#/gallery/345, last access: 1 June 2015.

Duan, Z. and Bastiaanssen, W.: Estimating water volume variations in lakes and reservoirs from four operational satellite altimetry databases and satellite imagery data, Remote Sens. Environ., 134, 403-416, doi:10.1016/j.rse.2013.03.010, 2013.

ESA: Sentinel 3, retrieved from Copernicus, observing the Earth: http://www.esa.int/OurActivities/Observing_theEarth/ Copernicus/Sentinel-3, last access 15 June 2015.

Ezer, T. and Liu, H.: On the dynamics and morphology of extensive tidal mudflats: Integrating remote sensing data with an inundation model of Cook Inlet, Alaska, Ocean Dynam., 60, 13071318, doi:10.1007/s10236-010-0319-x, 2010. 
Fraser, C. S. and Ravanbakhsh, M.: Performance of DEM generation technologies in coastal environments, 7th International Symposium on Digital Earth, 23-25 August 2011, Perth, Australia, 40-49, 2011.

García-Pintado, J., Mason, D., Dance, S., Cloke, H., Neal, J., Freer, J., and Bates, P.: Satellite-supported flood forecasting in river networks: A real case study, J. Hydrol., 523, 706-724, doi:10.1016/j.jhydrol.2015.01.084, 2015.

Getirana, A. C., Bonnet, M.-P., Calmant, S., Roux, E., Rotunno Filho, O. C., and Mansur, W. J.: Hydrological monitoring of poorly gauged basins based on rainfall-runoff, J. Hydrol., 379, 205-219, doi:10.1016/j.jhydrol.2009.09.049, 2009.

Giustarini, L., Matgen, P., Hostache, R., Montanari, M., Plaza, D., Pauwels, V. R. N., De Lannoy, G. J. M., De Keyser, R., Pfister, L., Hoffmann, L., and Savenije, H. H. G.: Assimilating SARderived water level data into a hydraulic model: a case study, Hydrol. Earth Syst. Sci., 15, 2349-2365, doi:10.5194/hess-152349-2011, 2011.

Gorokhovich, Y. and Voustianiouk, A.: Accuracy assessment of the processed SRTM-based elevation data by CGIAR using field data from USA and Thailand and its relation to the terrain characteristics, Remote Sens. Environ., 104, 409-415, doi:10.1016/j.rse.2006.05.012, 2006.

Horritt, M. S.: A methodology for the validation of uncertain flood inundation models, J. Hydrol., 326, 153-165, doi:10.1016/j.jhydrol.2005.10.027, 2006.

Islam, R. Z., Begum, S. F., Yamaguchi, Y., and Ogawa, K.: Distribution of suspended sediment in the coastal sea off the GangesBrahmaputra River mouth: observation from TM data, Marine Syst., 32, 307-321, doi:10.1016/S0924-7963(02)00045-3, 2002.

Jarihani, A., Callow, J., Johansen, K., and Gouweleeuw, B.: Evaluation of multiple satellite altimetry data for studying inland water bodies and river floods, J. Hydrol., 505, 78-90, doi:10.1016/j.jhydrol.2013.09.010, 2013.

Jarihani, A., McVicar, T., Van Niel, T., Emelyanova, I., Callow, J., and Johansen, K.: Blending Landsat and MODIS Data to Generate Multispectral Indices: A Comparison of "Index-then-Blend" and "Blend-then-Index" Approaches, Remote Sensing, 6, 92139238, doi:10.3390/rs6109213, 2014

Jarihani, A., Callow, J., McVicar, T., Van Niel, T., and Larsen, J.: Satellite-derived Digital Elevation Model (DEM) selection, preparation and correction for hydrodynamic modelling in large, low-gradient and data-sparse catchments, J. Hydrol., 524, 489506, doi:10.1016/j.jhydrol.2015.02.049, 2015.

Jung, C. H., Hamski, J., Durand, M., Alsdorf, D., Hossain, F., Lee, H., and Hasan, K.: Characterization of complex fluvial systems using remote sensing of spatial and temporal water level variations in the Amazon, Congo, and Brahmaputra Rivers, Earth Surf. Proc. Land., 35, 294-304, doi:10.1002/esp.1914, 2010.

Karlsson, J. M. and Arnberg, W.: Quality analysis of SRTM and HYDRO1K: a case study of flood inundation in Mozambique, Int. J. Remote Sens., 32, 267-285, doi:10.1080/01431160903464112, 2011.

Khan, S. I., Hong, Y., Vergara, H. J., Gourley, J. J., Brakenridge, G. R., De Groeve, T., and Yong, B.: Microwave Satllite Data for Hydrologic Modelling in Ungauged Basins, IEEE Geosci. Remote Sens. Lett., 9, 663-667, doi:10.1109/LGRS.2011.2177807, 2012.
Kim, J., Lu, Z., Lee, H., Shum, C. K., Swarzenski, C. M., Doyle, T. W., and Baek, S.-H.: Integrated analysis of PALSAR/Radarsat-1 InSAR and ENVISAT altimeter data for mapping of absolute water level changes in Louisiana wetlands, Remote Sens. Environ., 113, 2356-2365, 2009.

Kumar, A., Narayana, A., and Jayappa, K.: Shoreline changes and morphology of spits along southern Karnataka, west coast of India: A remote sensing and statistics-based approach, Geomorphology, 120, 133-152, doi:10.1016/j.geomorph.2010.02.023, 2010.

León, J. G., Calmant, S., Seyler, F., Bonnet, M.-P., Cauhopé, M., Frappart, F., and Fraizy, P.: Rating curves and estimation of average water depth at the upper Negro, J. Hydrol., 328, 481-496, doi:10.1016/J.JHYDROL.2005.12.006, 2006.

Li, S., Sun, D., Goldberg, M., and Stefanidis, A.: Derivation of 30-m-resolution water maps from TERRA/MODIS and SRTM, Remote Sens. Environ., 134, 417-430, doi:10.1016/j.rse.2013.03.015, 2013.

Liew, S. C., Gupta, A., Wong, P. P., and Kwoha, L. K.: Recovery from a large tsunami mapped over time: The Aceh coast, Sumatra, Geology, 114, 520-529, doi:10.1016/j.geomorph.2009.08.010, 2010.

Lillesand, T., Kiefer, R. W., and Chapman, J. W.: Remote sensing and image interpretation, 5th Edn., John Wiley and sons, Hobone, NJ, USA, 2004.

Long, S., Fatoyinbo, T., and Policelli, F.: Flood extent mapping for Namibia using change detection and thresholding with SAR, Environ. Res. Lett., 9, 035002, doi:10.1088/1748-9326/9/3/035002, 2014.

Mason, D. C., Horritt, M. S., Dall'Amico, J. T., and Scott, T. R.: Improving River Flood Extent Delineation From Synthetic Aperture Radar Using Airborne Laser Altimetry, IEEE T. Geosci. Remote, 45, 3932-3943, doi:10.1109/TGRS.2007.901032, 2007.

Mason, D. C., Scott, T. R., and Dance, S. L.: Remote sensing of intertidal morphological change in Morcambe Bay, U,K., between 1991 and 2007, Estuar. Coast. Shelf Sci., 87, 487-496, doi:10.1016/j.ecss.2010.01.015, 2010.

Matgen, P., Montanari, M., Hostache, R., Pfister, L., Hoffmann, L., Plaza, D., and Savenije, H.: Towards the sequential assimilation of SAR-derived water stages into hydraulic models using the Particle Filter: proof of concept, Hydrol. Earth Syst. Sci., 14, 17731785, doi:10.5194/hess-14-1773-2010, 2010.

Mcmillan, H., Hreinsson, E., Clark, M., Singh, S., Zammit, C., and Uddstrom, M.: Operational hydrological data assimilation with the recursive ensemble Kalman filter, Hydrol. Earth Syst. Sci., 17, 21-38, doi:10.5194/hess-17-21-2013, 2013.

Meijerink, A. M., Bannert, D., Batelaan, O., Lubczynski, M. W., and Pointet, T.: Remote sensing applictions to groundwater, Series on Groundwater, UNESCO, Paris, France, 2007.

NOAA, S. I.: Jason3, retrieved from: http: //www.nesdis.noaa.gov/jason-3/?CFID=

731ecb89-8379-48fc-ad50-9546e71739\&CFTOKEN=0, last access: 29 May 2015.

Noh, S., Tachikawa, Y., Shiiba, M., and Kim, S.: Applying sequential Monte Carlo methods into a distributedhydrologic model: lagged particle filtering approach with regularization, Hydrol. Earth Syst. Sci., 15, 3237-3251, doi:10.5194/hess-15-32372011, 2011. 
Owe, M., Brubaker, K., Ritchie, J., and Albert, R.: Remote sensing and Hydrology, 2000, IAHS, Wallingford, OX, UK, 2001.

Papa, F., Bala, S. K., Pandey, R. K., Durand, F., Gopalakrishna, V. V., Rahman, A., and Rossow, W. B.: Ganga-Brahmaputra river discharge from Jason-2 radar altimetry: An update to the longterm satellite-derived estimates of continental freshwater forcing flux into the Bay of Bengal, J. Geophys. Res., 117, C11021, doi:10.1029/2012JC008158, 2012.

Pavelsky, T., Morrow, R., Peterson, C., Andral, A., Bronner, E., and Srinivasan, M.: SWOT 101: A Quatum Improvement of Oceanography and Hydrology from the Next Generation Altimeter Mission, retrieved from: Surface Water and Ocean Topography: https://swot.jpl.nasa.gov/files/swot/ SWOT-101Jan2015.pdf, last access: 29 May 2015.

Penton, D. J. and Overton, I. C.: Spatial modelling of floodplain inundation combining satellite imagery and elevation models, MODSIM 2007 International Congress on Modelling and Simulation, Modelling and Simulation Society of Australia and New Zealand CSIRO, Clayton south, Vic, Australia, 2007.

Pereira-Cardenal, S. J., Riegels, N. D., Berry, P. A. M., Smith, R. G., Yakovlev, A., Siegfried, T. U., and Bauer-Gottwein, P.: Real-time remote sensing driven river basin modeling using radar altimetry, Hydrol. Earth Syst. Sci., 15, 241-254, doi:10.5194/hess-15-2412011, 2011.

Quinn, P. F., Hewett, C. J. M., Muste, M., and Popescu, I.: Towards new types of water-centric collaboration, Proceedings of the Institution of Civil Engineers: Water Management, 163, 3951, doi:10.1680/wama.2010.163.1.39, 2010.

Ričko, M., Birkett, C., Carton, J., and Crétauxc, J.-F.: Intercomparison and validation of continental water, J. Appl. Remote Sens., 6, 061710, doi:10.1117/1.JRS.6.061710, 2012.

Santos da Silva, J., Roux, E., Filho, O., Bonne, M. P., Seyler, F., and Calmant, S.: 3D Selection of Envisat Data for Improved Water Stage Times Series on the Rio Negro and Adjacent Wetlands (Amazon Basin), 2nd Hydrospace Workshop, 07_06, 1214 November 2007, ESA, Geneva, 2007.

Santos da Silver, J., Calmant, S., Seyler, F., Lee, H., and Shum, C.: Mapping of the extreme stage variations using ENVISAT altimetry in the Amazon basin rivers, Int. Water Technol. J., 2, 14-25, 2012.

Sarhadi, A., Soltani, S., and Modarres, R.: Probabilistic flood inundation mapping of ungauged rivers: Linking GIS techniques and frequency analysis, J. Hydrol., 458-459, 68-86, doi:10.1016/j.jhydrol.2012.06.039, 2012.

Schumann, G., Matgen, P., Pappenberger, F., Black, A., Cutler, M., Hoffmann, L., and Pfister, L.: The Refix Model: Remote Sensing Based Flood Modelling, ISPRS Commission VII Mid-term Symposium "Remote Sensing: From Pixels to Processes", Enschede, the Netherlands, 2006.

Schumann, G., Matgen, P., Hoffmann, L., Hostache, R., Pappenberger, F., and Pfister, L.: Deriving distributed roughness values from satellite radar data for flood inundation modelling, J. Hydrol., 344, 96-111, doi:10.1016/j.jhydrol.2007.06.024, 2007.

Schumann, G., Matgen, P., Cutler, M., Black, A., Hoffmann, L., and Pfister, L.: Comparison of remotely sensed water stages from LiDAR,topographic contours and SRTM, Photogram. Remote Sens., 63, 283-296, doi:10.1016/j.isprsjprs.2007.09.004, 2008.

Schumann, G. J.-P., Neal, J., Voisin, N., Andreadis, K., Pappenberger, F., Phanthuwongpakdee, N., and Bates, P.: A first large- scale flood inundation forecasting model, Water Resour. Res., 49, 6248-6257, doi:10.1002/wrcr.20521, 2013.

Schumann, G. J.-P., Bates, P., Neal, J., and Andreadis, K.: Measuring and Mapping Flood processes, in: Hydro-Meteorological Hazards, Risks, and Disasters edited by: Paron, P. and Di Baldassare, G., Elsevier, Amsterdam, the Netherlands, 35-64, 2015.

Seyler, F., Calmant, S., Santos da Silva, J., León, G. J., Frappart, F., Bonnet, M.-P., Filizola, N., Roux, E., Cochonneau, G., Zoppas Costi, A.-C., De, O. E., Guyot, J.-L., and Seyler, P.: New perspectives in monitoring water resources in large tropical transboundary basins based on the combined used of remote sensing and radar altimetry, in: Improving Integrated Surface and Groundwater Resources Management in a Vulnerable and Changing World, IAHS Publication, Wallingford OX, UK, 282288, doi:10.13140/2.1.5101.0569, 2009.

Siddique-E-Akbor, A. H., Hossain, F., Lee, H., and Shum, C. K.: Inter-comparison study of water level estimates derived from, Remote Sens. Environ., 115, 1522-1531, 2011.

Skakun, S.: A neural network approach to flood mapping using satellite imagery, Comput. Inform., 29, 1013-1024, 2010.

Smith, L. C.: Satellite Remote Sensing of River Innundation Area, Stage and Discharge: A review, Hydrol. Process., 11, 1427-1439, 1997.

Stephens, E., Bates, P., Freer, J., and Mason, D.: The impact of uncertainty in satellite data on the assessment of flood inundation models, J. Hydrol., 414-415, 162-173, doi:10.1016/j.jhydrol.2011.10.040, 2012.

Sun, W., Ishidaira, H., and Bastola, S.: Estimating discharge by calibrating hydrological model against water surface width measured from satellites in large ungauged basins, Annu. J. Hydraul. Eng., 53, 49-54, 2009.

Sun, W., Ishidaira, H., and Bastola, S.: Towards improving river discharge estimation in ungauged basins: calibration of rainfallrunoff models based on satellite observations of river flow width at basin outlet. Hydrol. Earth Syst. Sci., 14, 2011-2022, doi:10.5194/hess-14-2011-2010, 2010.

Syvitski, J. P., Overeem, I., Brakenridge, R. G., and Hannon, M.: Floods, floodplains, delta plains - A satellite imaging approach, Sediment. Geol., 267-268, 1-14, doi:10.1016/j.sedgeo.2012.05.014, 2012.

Tarpanelli, A., Barbetta, S., Brocca, L., and Moramarco, T.: River Discharge Estimation by Using Altimetry Data and Simplified Flood Routing Modeling, Remote Sensing, 5, 4145-4162, doi:10.3390/rs5094145, 2013.

Vermeulen, C. J., Barneveld, H. J., Huizinga, H. J., and Havinga, F. J.: Data-assimilation in flood forecasting using time series and satellite data, International conference on innovation advances and implementation of flood forcasting technology, ACTIF/Floodman/FloodRelief, Tromso, 2005.

Villladsen, H., Andersen, O., and Stenseng, L.: Annual cycle in lakes and rivers from cryosat-2 altimetry - the brahmaputra river, IEEE International Geoscience and Remote Sensing Symposium (IGARSS), 13-18 July 2014, Quebec, Canada, 894-897, doi:10.1109/IGARSS.2014.6946569, 2014.

Westahoff, R., Huizinga, J., Kleuskens, M., Burren, R., and Casey, S.: ESA Living Planet Symposium, 686, ESA Communications, Bergen, Norway, 2010.

Woldemicheal, A., Degu, A., Siddique-E-Akbor, A., and Hossain, F.: Role of Land-Water Classification and Manning's Roughness 
Parameter in Space-Borne Estimation of Discharge for Braided Rivers: A Case Study of the Brahmaputra River in Bangladesh, IEEE J. Select. Top. Appl. Earth Obs. Rem. S., 1939-1404, 395403, doi:10.1109/JSTARS.2010.2050579, 2010.

Yan, K., Di Baldassarre, G., Solomatine, D., and Schumann, G.: A review of low-cost space-borne data for flood modelling: topography, flood extent and water level, Hydrol. Process., 29, 33683387, doi:10.1002/hyp.10449, 2015.
Yang, C. and Ouchic, K.: Analysis of bar morphology using multi-temporal and multi-sensor satellite images: Example from the Han Estuary, Korea, Mar. Geol., 311-314, 17-31, doi:10.1016/j.margeo.2012.04.004, 2012.

Zhang, J., Xu, K., Yang, Y., Qi, L., Hayashi, S., and Watanabe, M.: Measuring water storage fluctuations in Lake Dongting, China, by Topex/Poseidon satellite altimetry, Environ. Monit. Assess., 115, 23-37, doi:10.1007/s10661-006-5233-9, 2006. 